\title{
Linking Quality Improvement and Energy Efficiency/Waste Reduction
}
R. E. Lewis
N. L. Moore

April 1995

Prepared for the U.S. Department of Energy under Contract DE-AC06-76RLO 1830

Pacific Northwest Laboratory

Operated for the U.S. Department of Energy by Battelle Memorial Institute 


\title{
DISCLAIMER
}

This report was prepared as an account of work sponsored by an agency of the United States Government. Neither the United States Government nor any agency thereof, nor Battelle Memorial Institute, nor any of their employees, makes any warranty, expressed or implied, or assumes any legal liability or responsibility for the accuracy, completeness, or usefulness of any information, apparatus, product, or process disclosed, or represents that its use would not infringe privately owned rights. Reference herein to any specific commercial product, process, or service by trade name, trademark, manufacturer, or otherwise does not necessarily constitute or imply its endorsement, recommendation, or favoring by the United States Government or any agency thereof, or Battelle Memorial Institute. The views and opinions of authors expressed herein do not necessarily state or reflect those of the United States Government or any agency thereof.

\author{
PACIFIC NORTHWEST LABORATORY \\ operated by \\ BATTELLE MEMORIAL INSTITUTE \\ for the \\ UNITED STATES DEPARTMENT OF ENERGY \\ under Contract DE-ACO6-76RLO 1830
}

Printed in the United States of America

Available to DOE and DOE contractors from the

Office of Scientific and Technical Information, P.O. Box 62, Oak Ridge, TN 37831; prices available from (615) 576-8401. FTS 626-840t.

Available to the public from the National Technical Information Service, U.S. Department of Commerce, 5285 Port Royal Rd, Springfield, VA 22161. 


\section{DISCLAIMER}

Portions of this document may be illegible in electronic image products. Images are produced from the best available original document. 
PNL-10536

AD-902

\title{
Linking Quality Impŕovement and Energy Efficiency/Waste Reduction
}

\author{
R. E. Lewis \\ N. L. Moore
}

April 1995

Prepared for

the U.S. Department of Energy

under Contract DE-AC06-76RLO 1830

Pacific Northwest Laboratory

Richland, Washington 99352

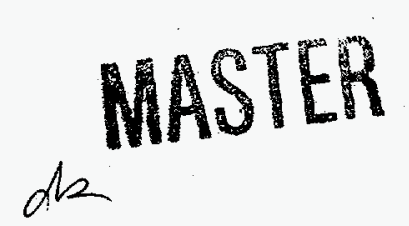




\section{Executive Summary}

For some time industry has recognized the importance of both energy efficiency/waste reduction (ee/wr) and quality/manufacturing improvement. However, industry has not particularly recognized that manufacturing efficiency is, in part, the result of a more efficient use of energy. For that reason, the energy efficiency efforts of most companies have involved admonishing employees to "save energy." Few organizations have invested resources in training programs aimed at increasing energy efficiency and reducing waste. We aim to demonstrate how existing utility and government training and incentive programs can be leveraged to increase ee/wr and benefit both industry and consumers.

Fortunately, there are a variety of training tools and resources that can be applied to educating workers on the benefits of energy efficiency and waste reduction. These range from privately produced videos to government-funded research briefs. In short, there is no lack of tools to be applied to ee/wr training. What is lacking is a method of integrating ee/wr training with other important organizational needs. Currently, ee/wr training is a low priority among managers who see high investments, long paybacks, and more pressing needs in customer satisfaction and quality improvement. Unless some action is taken, ee/wr efforts will continue to receive low priority and little funding.

The key, therefore, is to leverage ee/wr investments with other organizational improvement programs. There are significant strides to be made by training industry to recognize fully the contribution that energy efficiency gains make to the bottom line. The federal government stands in the unique position of being able to leverage the investments already made by states, utilities, and manufacturing associations by coordinating training programs and defining the contribution of energy-efficiency practices. These aims can be accomplished by

- developing better measures of energy efficiency and waste reduction

- promoting methods of leveraging manufacturing efficiency programs with energy efficiency concepts

- helping industry understand how ee/wr investments can increase profits

- promoting research on the needs of, and most effective ways to, reach the small- and mediumsized businesses that so often lack the time, information, and finances to effectively use the hardware and training technologies available.

These goals can be accomplished by coordinating investments and programs already funded by the federal government. The U.S. Department of Energy (DOE), which already funds energy analysis centers and operates power marketing administrations, stands as the agency most able to create synergies among the programs of state, municipal, and other federal agencies and industry. 


\section{Contents}

Executive Summary $\ldots \ldots \ldots \ldots \ldots \ldots \ldots \ldots \ldots \ldots \ldots \ldots \ldots$

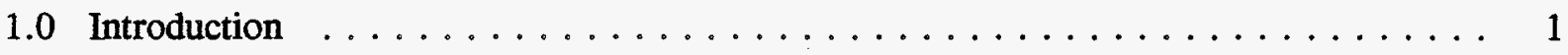

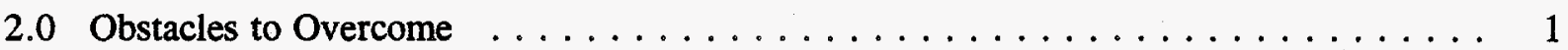

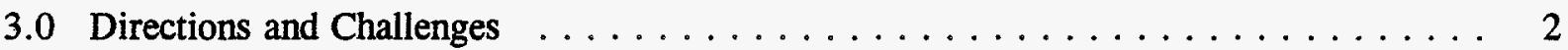

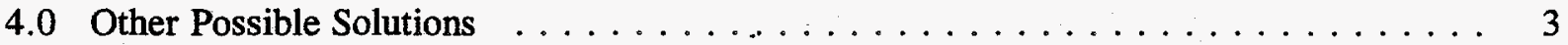

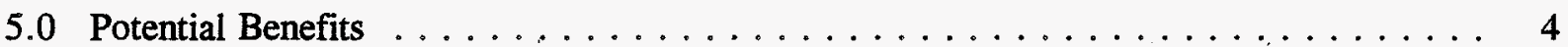

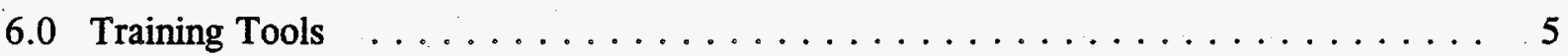

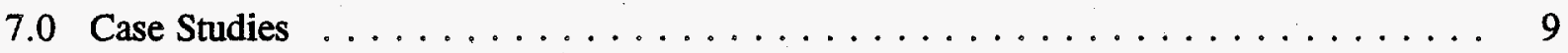

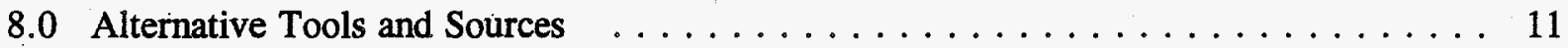

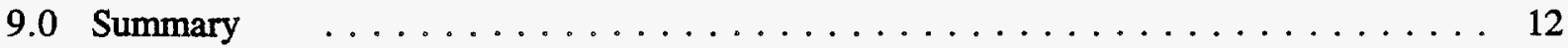

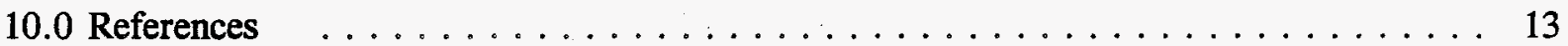

Attachment - Sources for Training Tools $\ldots \ldots \ldots \ldots \ldots \ldots \ldots \ldots \ldots$ 


\subsection{Introduction}

Quality improvement and training efforts have "gone mainstream" in private industry because of increased competition and the average consumer's greater emphasis on product quality. As consumers demanded products of high quality as well as low price, businesses found that their need for highly skilled, trained, and empowered workers gave them the incentive to invest in their workers. Whereas quality management, employee empowerment, and training concepts were limited to "elite" organizations just 10 years ago, there are probably few business managers today who do not understand the importance of having a well-trained workforce and the impact those workers can have on product quality and profitability.

In the same way that increased competition and an emphasis on quality prompted industry to focus on total quality management (TQM) and training, increased environmental regulation and energy and disposal costs have spurred interest in energy efficiency (ee) and waste reduction (wr). For instance, in less than 3 years, over 1,150 organizations have joined the Environmental Protection Agency's (EPA's) Green Lights program to improve lighting quality while reducing energy costs (Ref. 1). Organizations are also reducing the costs of doing business by developing manufacturing processes that recycle solvents, increase raw material utilization, use more efficient technologies, and reduce waste generation.

Despite becoming popular at roughly the same time, the trends to be a "green" business, as well as a producer of quality goods and services, have remained fairly independent of each other. In few cases are training efforts directed toward quality improvement aimed simultaneously at waste reduction. Similarly, training efforts to improve energy efficiency are often not coordinated with process improvement training or employee skill enhancement. As a result, the gains in energy efficiency produced by TQM-based improvements are understated, and the opportunity to leverage quality training and empowerment programs to yield greater successes in ee/wr is lost.

\subsection{Obstacles to Overcome}

Training and employee education is a difficult and time- and money-consuming process partly because of the lack of basic skills often found in the workforce. "[E]xecutives find it just too daunting to have to lay the groundwork of reading, writing, and arithmetic before they can even begin to teach employees new skills that arise from the latest technology or work reorganizations" (Ref. 2; p. 31). Compounding the difficult task of retraining workers is the lack of support most companies face. The incentive to upgrade the skills of the workforce to promote worker flexibility, waste reduction, or any other aim is not sweetened by tax deductions or rebates. These incentives go instead to capital improvement and hardware replacement projects. Companies thus generally find it easier to save energy and money by upgrading equipment and installing passive energy-efficient systems (such as 
improved lights and motion sensors). The costs of promoting the active involvement of employees in ee/wr are borne solely by the organization and may not provide a rate of return that justifies the expense.

As difficult as it may be for large companies to promote ee/wr through worker training, it is even more so for small- and medium-sized companies. "These do not normally have their own energy experts, nor do they have enough information on energy-saving measures, a market overview or knowledge of the cost-benefit relation of such measures" (Ref. 3; p. 279). In a study of German industry, Gruber and Brand found most utility subsidy programs "poorly adapted to the problems of small- and medium-sized firms" (Ref. 3; p. 282). Individuals in these firms typically spend less time in training, lack the time to devote to learning about conservation programs, and rate other tasks as more important.

As a result, small- and medium-sized firms are less likely to make use of consultants or conservation programs, even when provided free by utilities. Many of the recommendations offered to involve these firms more in energy conservation programs concern making information more readily available through trade associations. Interestingly, 77\% of companies favored subsidies for energy-saving measures, although $82 \%$ of firms claim they are of little or no importance in deciding whether to join an ee/wr program (Ref. 3). The authors infer it is the time and administrative cost of managing an energy conservation program, not the financial cost, that is the primary hurdle for small- and mediumsized businesses.

\subsection{Directions and Challenges}

Great savings can be obtained from encouraging ee/wr practices in employee training, workplace restructuring, and process improvement interventions. However, several challenges and potential barriers must be addressed.

First, better measures and concepts of ee/wr must be defined. Energy-efficiency and wastereduction efforts have been measured and promoted by using conservative approaches that understate the savings that can be attributed to ee/wr efforts and limit the methods by which ee/wr gains can be made. For instance, with the exception of raising employee awareness levels using conservation/ recycling programs, training is not considered an ee/wr tool and is not supported financially by utilities or federal programs. Thus, most organizations that train employees in quality production methods and achieve reductions in scrap, rework, and cycle time fail to measure their success in energy-efficiency terms. The tendency to avoid thinking of "quality management" methods as energy-efficiency methods needs to be overcome.

Better measures of energy savings, energy efficiency, and waste reduction would more accurately gauge the conservation gains of organizations and tie them more closely to improvements in production controls and profitability measures. With better measures, a company that is more profitable as a 
result of improved manufacturing processes could determine how much of the increased profit is due to reduced cycle time, increased productivity, decreased energy use, etc. At that point, additional investments can be planned knowing their return is based on their effect on energy usage versus labor cost, for example. Presently, most organizations do not think of ee/wr in these terms and may thus understate energy gains, misunderstand how energy savings and waste reduction can be achieved, and may unintentionally forego opportunities to increase ee/wr.

Should separating the contribution of ee/wr to the bottom line become too difficult, the advantages of leveraging training dollars spent on quality and process improvement into ee/wr might prove an attractive alternative. The Congressional Office of Technology Assessment (OTA) notes that managers often want energy-efficiency programs to pay back in 2 years, representing an internal rate of return of 60 percent--an exceedingly high threshold (Ref. 4). Projects that return more than the market cost of capital, but under the internal threshold fall into the "efficiency gap" of projects that are "presumably cost-effective, yet not undertaken." If managers were to acknowledge that training could serve both quality and ee/wr ends, one investment would generate two types of returns, thereby reducing the need for capital and lowering the internal rate of return of each. Energy-efficiency and waste-reduction projects that would ordinarily have fallen into the efficiency gap are undertaken.

According to the OTA, narrowing the efficiency gap further requires information: "Energy costs do not command the attention of senior management and do not garner the resources needed to implement improvements." At lower levels of the organization, staff are now running so lean in most companies that the time to take on the added responsibility of ee/wr just is not there. Those with the time and resources do not have the awareness, and the shop workers and engineers with the knowledge do not have the time. Information will help top management assess more fairly the benefits of ee/wr and encourage them to reallocate their time, financial, and human resources to obtain more ee/wr savings. Understanding how ee/wr and other productivity improvement projects can be leveraged will help supervisors and workers on the shop floor allocate their time more effectively.

\subsection{Other Possible Solutions}

Progress can be made against these obstacles by businesses teaming with the Department of Labor's (DOL's) Learning Consortium. The Consortium's task to help small- and medium-sized businesses obtain technical assistance can be accomplished by coordinating the activities of utility programs, such as Southern California Edison's (SCE's) Customer Technology Application Center (CTAC). Organizations such as CTAC, in turn, leverage federal and state investments in training by facilitating the contact between private industry and programs, such as the Job Partnership Training Act and state-funded, industry-specific training programs.

At least one business association leader believes teaming among an even broader set of organiza-

tions may be necessary: "A combined approach relying on associations, unions, the trade press, 
Manufacturing Technology Centers (MTCs), the U.S. Department of Energy (DOE) labs, and the education community would be required to effectively reach the manufacturing workforce of today and the future" (Ref. 5; p. 4).

More needs to be known about the particular ee/wr difficulties faced by small- and medium-sized businesses. The case studies illustrated in this study concern mainly large businesses, which may not have the same time, financial, and managerial concerns or resources as smaller businesses. The Gruber and Brand (Ref. 3) study of German small- and medium-sized businesses is a start, but it is not clear that those findings are valid for U.S. businesses. Until more is known about the special needs of this business sector it will be difficult to ensure their full participation in ee/wr efforts.

Despite their successes at helping smaller businesses, technology extension programs currently "cannot reach more than a small fraction of the country's 355,000 small- and medium-sized manufacturing firms" (Ref. 6; p. 54). There are opportunities to link DOE/DOL programs with these state services as well as other organizations that serve businesses, such as the National Federation of Independent Businesses, manufacturing associations, and the Energy Analysis and Diagnostic Centers (EADCs). Building on the successes of the state programs--timely consulting, a focus on quality and profitability, and quality training--by leveraging federal and private dollars appropriately is a powerful economic development and energy-efficiency tool.

\subsection{Potential Benefits}

There are very few explicit links among worker training and retraining programs and ee/wr efforts. The drive to connect them closely in the few utilities that have done so is economic necessity. Yet, large savings could be gained by coordinating investments in ee/wr with worker training and workplace improvement, such as the following.

National Benefits. Employment training programs at the federal level often overlap and are poorly monitored (Ref. 7). More narrowly focused training programs may be more effective, but they, too, are likely to overlap if not coordinated. For instance, efforts to reach workers to explain ee/wr concepts may duplicate efforts to reach workers and examine the quality of work life. Similarly, the attempt by the National Center for the Workplace to develop better performance measures for firm, industry, and society use could easily be coordinated with measures of energy savings and waste reduction, but would not be if left to happenstance.

Utility Benefits. Utilities faced with eroding customer bases, such as Northeast Utilities and Southern California Edison, benefit by stabilizing their industrial, hence residential, clientele. Training and process improvement programs also fulfill the goals of demand-side management programs, such as reducing energy demands during peak periods and, in general, increasing the productivity of the client population. Investments in community-based development organizations may also increase 
returns on "stranded investments"--those not producing an income stream for the utility despite previous substantial investments in infrastructure.

Private Industry Benefits. Small- and medium-sized firms are commonly acknowledged as the engine behind the nation's job creation power. They would benefit from programs that placed the training resources of larger organizations within their budget. The aid provided by state-sponsored programs could be spread over a larger population of businesses with the appropriate coordination of DOL and DOE programs.

The following chapters describe training tools and resources required to accomplish both ee/wr and quality improvement in industry.

\subsection{Training Tools}

Educational and training tools are provided by various sources, including government agencies, universities, and the private sector. Tools can be provided in three basic forms:

- services that are rendered by the provider to the interested organization

- products that are delivered to the organization in the form of publications, hardware, or information

- training that is provided to the interested organization to enable it to use the product or perform the service on itself:

All of the above three tools can be used to train employees on energy efficiency and waste reduction practices and, often, a product or method that was not intended to be a training or educational tool can serve that purpose. These types of tool have been listed as well.

Industrial Engineering-Type Tools. Industrial engineering (IE) tools include cause-effect analyses, IDEF ${ }^{(a)}$ modeling, productivity audits, and other production engineering analytical techniques.

Also included are services commonly offered under the title "management consulting," such as brainstorming sessions, benchmarking studies, workshops, and staff and organizational analyses. These tools are used to identify sources of waste and inefficiency and methods to improve productivity through work redesign, hardware upgrades, and/or improved production/scheduling methods.

These tools are commonly offered by private sector consulting agencies, software developers, and research institutes as well as Manufacturing Technology Centers (MTCs), Industrial Assessment

(a) Icam DEFinition language (ICAM is the acronym for Integrated Computer-Aided Manufacturing). 
Centers (IACs), and, to a limited degree, utilities. (Innovative utilities, such as Northeast Utilities, Southern California Edison, and Boston Edison, provide a wide range of productivity and organizational services.) Primarily, the tools available are services, such as those offered by DOE's IACs. Private consulting groups often provide services as well as engage in training and develop products (computer programs, books, measurement tools) that they sell on the market.

Training workshops include such topics as process simulation through flowcharting, total quality management (TQM) with an environmental/waste reduction focus, and empowering employees to determine the root causes of excess waste generation or energy inefficiencies (Ref. 8). In its regional editions, The Environmental Directory lists hundreds of consulting, training, and waste services companies (Ref. 9). State industrial extension services are another source of companies that provide IE tools; they often refer clients to certified consultants and professionals.

Energy Audits. Energy audits identify ee/wr opportunities and are provided by utilities, Energy Analysis and Diagnostic Centers (EADCs), MTCs, and the private sector. Utilities and EADCs seem to provide the majority of audits, which are free to participating organizations. EADC/IAC audits result in a confidential report to management, whereas utility-sponsored audits can qualify participating organizations for equipment upgrade subsidies. MTCs sometimes provide energy audits as a part of a larger productivity audit, but do not generally specialize in such work.

Training in energy auditing may be obtained from training organizations but is not available from the EADCs, MTCs, or utilities. An audit conducted at a facility, however, may serve as a learning device for the organization's employees.

Newsletters. Information can be obtained from regularly published newsletters sponsored by industry associations, such as the National Center for Manufacturing Sciences. Although we found none that focus specifically on ee/wr, we did find that pollution prevention and related topics were frequently discussed in the industry publications. Articles from the newsletters are informative and can be used as supplemental reading materials in training courses.

Fact Sheets. Unlike newsletters, fact sheets (and their cousin, checklists) are occasional publications that focus on specific topics. They are available from many sources, including state agencies such as the Minnesota Office of Waste Management, the North Carolina Agricultural Extension Service, and the Michigan Office of Waste Reduction Services. Fact sheets are often oriented toward specific industries and specific problems or issues. They often present lessons learned from companies within those industries and how regulators responded. Consequently, they are excellent training as well as information tools for both industry and academia.

Fact sheets are also used to describe government programs and research results. The DOE, for instance, regularly publishes fact sheets as a method for describing energy efficiency gains developed through its research programs. The Energy Information Administration (EIA), an agency within the DOE, publishes a broad array of documents on energy-related matters. 
Financial Tools. Limited effort has been invested to develop financial tools for pollution prevention. Private sources have generic financial analysis tools that must be customized, but the EPA has sponsored the development of financial analysis software specifically designed for pollution prevention. The package, P2/FINANCE, "is designed to simplify and quicken the task of organizing and analyzing cost data, calculating annual cash flows, and generating financial indicators for pollution prevention investments" (Ref. 10; p. 1).

The EPA has also funded publications that explain accounting methods for pollution prevention and list resources and contact persons in EPA's network for managerial accounting and capital budgeting.

Product Design Aid. Limited product design help is available through programs administered by the federal government. Programs funded by the DOE, for instance, are oriented toward technological advances in product design or raw materials and are generally limited to businesses or business consortia that propose and manage government contracts. The DOE's EADC/IAC programs, however, are readily available to small- and mid-sized businesses within the centers' operating area (150 miles). A limitation is that product design aid, as with general industrial-engineering tools, is limited to those centers designated as IACs (Ref. 11). Engineering consulting groups appear to be the primary sources of help regarding product design. Utilities with business outreach programs generally provide limited referral services. Thus, there are few training tools specifically related to product design improvement.

Research Reports/Briefs. The federal government funds and publishes extensive research in the pollution prevention and ee/wr areas. The EPA publishes an extensive set of project summaries and environmental research briefs targeted to regions and industries on relevant case studies and topics. DOE publications on a variety of research topics, including ee/wr, are available through databases as well as the DOE's Public Reading Rooms.

Private research institutes are another source of research information, though generally at a cost. Universities, of course, encourage publication by their faculty and are often interested in collaborative projects that provide a benefit to the organization and research for the faculty. Reports, briefs, and collaborative research all serve as educational/training vehicles for an organization.

Educational/Awareness Aids. Educational aids are produced by nearly every government agency with an interest in ee/wr, as well as private sources and universities. The EPA and DOE and, of course, the Department of Education, invest heavily in the development of programs, products, and services for education. The DOE, for instance, publishes a sourcebook for energy education (Ref. 12) as well as a description of education programs (Ref. 13).

Many government agencies fund curriculum development, as did the Department of Education with CHEMTREK and Echem (Ref. 14 and 15). Both are micro-scale chemistry courses (which reduce the amounts of chemicals and wastes generally produced in chemistry classes) developed for chemistry majors (CHEMTREK) and non-majors (Echem). The EPA has developed a booklet offering creative approaches to teaching ee/wr concepts called "Teaching Those Humans to Think" (Ref. 16). Finally, 
the DOE, at each of its laboratories and production sites, funds an extensive science education outreach program that consists of workshops, presentations, faculty and student internships, and educational products.

Resource guides are also available from the National Pollution Prevention Center for Higher Education (Ref. 8). The NPPCHE is also developing curriculum modules and case studies that can be used in coursework in a variety of fields, including accounting, business law, and operations research as well as chemistry and environmental engineering.

Videos. Production companies are now developing and marketing videos on various aspects of ee/wr, such as recycling and mitigating waste. Increasingly, companies are developing their own materials for training, education, and awareness purposes. Examples of videos are: "Grime goes green" by Video Arts; "Business and the environment: Lean, green, and mean" by Peters Group; and, "Managing to be green" by Pfeiffer \& Co., all referenced in (Ref. 17). An in-house video was developed by DOE for its employees and contractors (Ref. 18).

Resource Guides. Several resource guides, such as those for educational materials, have been mentioned above. Tedd Saunders' book, The Bottom Line of Green Is Black, contains an extended resource list and description of government agencies, and research, policy, and lobbying organizations with interests in pollution prevention (Ref. 19).

Research institutes often provide resource lists to their membership to guide lobbying and government grant requests. The government, in turn, collects information from the private and state government sectors and publishes guide books for both state governments and industry. A good example is the EPA booklet, "Pollution Prevention Incentives for States," which details the activities of federal grant recipients in the areas of technical assistance, technical training, and legislation and infrastructure, among others (Ref. 20).

Case Studies. Descriptions of programs and projects that are undertaken are provided by utilities, government, and the private sector. These are often available in magazines such as Environment Today, HRMagazine, Electrical World, and Industry World. Government agencies also publish case study series. See the Attachment to this report for detailed sources.

Legislative Information. Interpretations of legislation are provided by research institutes and industry associations to their subscribers/members in the form of newsletters and special reports. The EPA published guidelines to regulations and Executive Orders designed to facilitate compliance by highlighting key provisions and deadlines and listing agency contacts (Ref. 21). 


\subsection{Case Studies}

These case studies demonstrate how industry relies on the sources and uses the training tools outlined in the previous section. Many case studies are reported by utilities. A good example of a utility with an innovative program is Northeast Utilities. ${ }^{(a)}$ As the Northeast lost manufacturing jobs (1.1 million jobs since 1975; Ref. 22, p. 6), it faced an eroding customer base. Northeast Utilities found that some of these job losses occurred from businesses closing completely, but many other jobs were lost from the area because businesses relocated elsewhere. To help these customers become more competitive and entice them to remain within the utility's service area, Northeast Utilities started PRIME, an experimental program that teams the utility and select customers with certified consultants to analyze the customer's operations and produce competitive efficiencies, not just energy efficiencies. The benefit to the customer is an industrial/energy/management engineering analysis that can increase productivity as well as reduce energy costs and thereby make the customer more competitive and profitable. The utility gains a stable customer. Although no data are available yet, the utility believes that PRIME is an effective program for reaching and helping customers.

A similar program has been implemented at Southern California Edison (SCE), which also faced an eroding customer base because of California's tax structure and stringent air quality standards. Unlike Northeast Utilities, SCE's energy efficiency liaisons, called Energy Service Representatives (ESRs), work directly with the customer to obtain efficiencies through the implementation of new technologies, focus more strongly on customer needs and wants, and connect the customer with the relevant technical experts in SCE. The aim is to produce a cultural shift in SCE that makes the company more customerfocused and responsive to the market. Customers gain assistance with regulatory permitting, local ordinances, and production/service technologies (Ref. 23).

Training produced unanticipated benefits for Kraft General Foods (KGF) in Framingham, Massachusetts when it teamed with Boston Edison to reduce energy costs. As KGF installed new, more efficient technologies, workers received training on the new computer programs. Employees were involved in the selection of the solutions and technologies and trained extensively on the new hardware. As they became more proficient the machinery operators showed more initiative, job involvement, and foresight. As a result, the plant has achieved production efficiencies beyond those predicted from the energy efficiency improvements. ${ }^{(b)}$

Many companies that have developed in-house ee/wr training courses typically combine them with TQM and employee involvement efforts to achieve benefits similar to those at KGF. A diverse group of employees at Colgate-Palmolive, for instance, developed ENVIROPRIDE to promote energy efficiency, waste reduction, and rewards for environmentally friendly acts in all Colgate's technology and administrative divisions. The program is an attempt to raise environmental awareness in all employees

(a) Personal communication: Mike Fenefski, Northeast Utilities, July 13, 1994.

(b) Crowley, J. C., and J. P. Donoghue. "The Energy Efficiency Partnership: Kraft General Foods and Boston Edison Company." (Publication date unknown.) 
and get them to accept responsibility for improving the environmental performance of the organization. This effort mirrors the trend to remove sole responsibility for environmental programs from the Environment, Safety and Health (ES\&H) manager and distribute it more broadly through the organization (Ref. 19 and 23).

The same philosophy--that environmentally sound programs are the responsibility of everyone-holds at General Electric. Every plant manager as well as all engineering, transportation, and marketing employees are required to successfully complete training courses in environmental skills.

Businesses such as GE and Colgate-Palmolive are the exception. There are, however striking consistent patterns among the companies that promote environmentally sound and energy-efficient practices. These organizations:

- promote ee/wr and environmentally sound practices as part of their culture. They have an enduring commitment backed by their actions--no "program of the week." In many cases, companies built trust by starting their ee/wr programs small, building on successes, and keeping the programs focused on company goals.

- train and educate their workers. Internal training is "critical" at Veryfine, the juice manufacturer with a long and innovative history of energy and environmental awareness. Because workers at all levels of the organization are needed to make the program work, the training consists of organizational culture, awareness, TQM, and skills components.

- partner with suppliers and, in some cases, competitors. Apple Computer, for instance, partnered with competitors to develop a "no clean" electronic circuitboard that reduced operations steps and eliminated the use of chlorofluorocarbons (CFCs) in the manufacturing process. It also worked with suppliers to develop more energy-efficient and environmentally friendly packaging, as did Herman Miller, the furniture manufacturer (Ref. 19).

Utilities are not only working with their customers to promote ee/wr, but are training their own employees as well. SCE reworked its entire training program for ESRs to instill new cultural values and meet customer needs. ESRs needed to learn "better consulting skills, [how to] understand a customer's industry and individual business, and the need to be in partnership with the companies Southern California Edison serves" (Ref. 23; p.47). Training also had to deliver classes as they were needed--making it a TQM-oriented department as well. Counselors then coached the ESRs on how to implement the new skills they learned.

SCE also created a Business Retention Program to coordinate consultation with its Customer Technology Application Center (CTAC) and provide technology advice, information about tariffs, help 
with complying with environmental regulations and compliance, long-term energy trend data, and site selection assistance. The program has, since January 1992, helped preserve 31,000 jobs and represents the sale of 1.3 billion $\mathrm{kWhs}$ and revenue of $\$ 93$ million. ${ }^{(a)}$

Despite being successful, oriented toward the needs of business, and proven energy savers, utility programs have not received the publicity they deserve. A 1993 book that discusses the profitability of environmentally sound business practices details case studies from the food, service, manufacturing, consumer goods, and processing industries but makes no mention of utilities (Ref. 19).

Finally, lessons can be learned from industry experiences with state industrial extension agencies. The OTA finds that utility and state-sponsored technology extension/assistance services are promising vehicles for helping small- and medium-sized businesses (Ref. 24). For instance, Bradhart Inc. installed new computer numerically-controlled machine tools and a computer-based demand pull manufacturing system. The small ( $\$ 3$ million/year sales) company found itself out of credit and on the verge of disaster. "Because the managers did not appreciate how much training would cost, the company almost went under in an otherwise sensible move to modernize" (Ref. 24; p. 181).

Bradhart was helped through this crisis by the Michigan Modernization Service (MMS), a statesponsored industrial extension service. The OTA found these services to be highly efficient mechanisms to bring the latest technology to small- and medium-sized firms. Of the five programs OTA studied, all refer clients to training sources when necessary. Only the MMS, however, routinely includes training in its services. As a result, the other programs, in some cases, find "training that extension agents recommend, and companies are eager to get, is not available" (Ref. 24; p. 181).

\subsection{Alternative Tools and Sources}

Tools other than those outlined in Chapter 6 can be employed to help meet ee/wr goals. Efforts to improve the quality of work life, such as those sponsored by the DOL's Office of the American Workplace and the National Center for the Workplace, can also be used to reduce energy usage and waste. The use of work-at-home, 4-day, 10-hour schedules, job sharing, and other work design/ redesign efforts can lower energy usage and expense via less commuting and reducing the amount of office space to be heated/air conditioned.

The "virtual office" concept has been adopted with success by several companies. Employees have no permanent office but instead use common office areas equipped with workstations/ports that can be used to access voice and electronic mail and files. The companies that have successfully applied these "nonterritorial" offices find that employees spend more time with customers, increase point-of-contact sales, and enjoy the flexibility that a virtual office provides.

(a) "Southern California Edison Business Retention Program." (Promotional material supplied by the SCE Customer Technology Application Center and the Business Retention Program.) 
Energy-efficiency and waste-reduction goals can accrue from the decreased need for office space and less commuting. "Typically, an office that goes 'virtual' can reduce its space requirements by 25 percent to 50 percent" (Ref. $25 ;$ p. 36). Ernst and Young realized a $\$ 40$ million savings, Aetna \$2.5 million, and AT\&T \$24 million savings in real estate expenses. These figures likely include saved utility expenses as well as leasing and maintenance costs.

Not included in these savings is the cost of commuting. Employees report avoiding long commutes (simply to check in at an office). In many cases, employees go weeks without visiting a central office. It is unclear whether saving this fuel actually decreases total fuel usage (since employees may spend it visiting more clients), but it may nonetheless increase efficiency if more sales are generated, given the same amount of fuel.

The training needed to implement a "virtual office" is considerable, but is much like that recommended for an ee/wr intervention. Employees need to learn how to use new equipment, need to understand the reasons behind the change, and have the option to manage change at their own pace and learn new time- and self-management skills.

Other innovative approaches, which may understate ee/wr gains, exist. Several utilities have begun collaborating with community development organizations as a method of stabilizing neighborhoods and fostering businesses, hence developing residential and commercial customers. These programs are profitable for the utilities--Brooklyn Union Gas documented that its $\$ 250 \mathrm{~K}$ allocation to community grants "created a new gas load of 81 billion BTUs, which resulted in additional gross profit of $\$ 320,000 "$ (Ref. $26 ;$ p. 10). They are profitable also for the community; many of the development programs include jobs and training in building construction, weatherization, child care, and other economic skills. Moreover, the programs revitalize communities and provide opportunities for inner city and rural residents. Finally, buildings are refurbished instead of demolished and built anew, thus saving energy and raw materials.

Although training per se is not the aim of these initiatives, it is a crucial part of making them work and contributes to the larger workforce empowerment movement.

\subsection{Summary}

Most organizations recognize the benefits of programs that eliminate manufacturing steps and improve product quality. As they continue to discover these benefits, they also discover the advantages of having well-trained workers. Companies have not, for the most part, connected gains in profitability and product quality to improvements in energy efficiency as readily as they have to quality management. Consequently, the gains associated with ee/wr programs have been understated, and many cost-effective ee/wr programs that might have been undertaken received no support. 
There are significant and complementary links between quality and manufacturing efficiency and ee/wr. In most cases, manufacturing improvements and profitability gains can be improved if they are leveraged with small investments in ee/wr, and if ee/wr concepts are built into the training already needed to effect an improvement in manufacturing quality. Some large firms have discovered this and their experiences have been detailed in this report. For the small- and medium-sized business, however, access to resources--time, information, and money--is limited. As a result, these have not generally benefitted from the techniques and concepts that work in the larger companies.

Significant inroads are possible by coordinating the programs that serve individual companies well, but collectively do not maximize the benefit that could accrue to the nation. Utilities could be encouraged to think of ee/wr in terms broader than conservation and hardware upgrades; state extension services could be more strongly linked into federal training and industry investment programs, and federal dollars can be allocated to coordinating DOE and DOL programs that, to date, have addressed different sides of the same coin.

The data gathered by the OTA bear repeating. If managers continue to consider the operation of a production line or provision of a service to be their overriding goal, then ee/wr efforts will remain underfunded and too many profitable projects will remain in the "efficiency gap." Only when managers understand that the capital and time used to increase productivity can be leveraged into energysaving projects as well (and to generate returns on that investment), will ee/wr become a priority. Hitching ee/wr to the quality management wagon through the coordination of federal, state, utility, and industry programs appears to be the most promising method of improving ee/wr in industry.

\subsection{References}

1. U.S. Environmental Protection Agency (EPA). July 1993. Green Lights: An Enlightened Approach to Energy and Pollution Prevention. EPA 430-K-93-001.

2. Geber, B. January 1993 . "Train who to do what." Training, pp. 27-34.

3. Gruber, E., and M. Brand. April 1991. "Promoting energy conservation in small-and mediumsized companies." Energy Policy, pp. 279-287.

4. Office of Technology Assessment (OTA), U.S. Congress. 1993. Investment in Efficiency (pp. 117-124). Superintendent of Documents Report Y3.T 22/2:2 IN 2/7.

5. Kennedy, D. R. July 15, 1993. Statement before the Subcommittee on Technology, Environment, and Aviation of the Committee on Science, Space, and Technology, U.S. House of Representatives. 
6. Office of Technology Assessment (OTA), U.S. Congress. February 1990. Making Things Better: Competing in Manufacturing. OTA-ITE-443, U.S. Government Printing Office, Washington, D.C.

7. General Accounting Office (GAO), U.S. Congress. March 1994. Multiple Employment Training Programs: Most Federal Agencies Do Not Know If Their Programs Are Working Effectively. GAO/HEHS-94-88.

8. National Pollution Prevention Center for Higher Education. 1992. Directory of Pollution Prevention in Higher Education: Faculty and Programs.

9. The Environmental Directory. Earth Scope Corp., Capitola, California. (Published yearly.)

10. U.S. Environmental Protection Agency (EPA). January 1994. P2/Finance User's Manual. EPA 742-B-94-002.

11. Office of Industrial Technology (OIT), U.S. Department of Energy. March 1994. The OIT Year in Retrospect.

12. U.S. Department of Energy (DOE). 1993. Energy Education Resources. DOE/EIA-0546-93.

13. U.S. Department of Energy (DOE). 1992. Education Progräms Catalog. DOE/ER-0540-P0.

14. Thompson, S. 1990. CHEMTREK: Small-scale Experiments for General Chemistry. Allyn and Bacon, Boston.

15. Thompson, S., and J. Resseguie. 1994. Echem. Kendall/Hunt Publishing Company, Dubuque, Iowa.

16. U.S. Environmental Protection Agency (EPA). "Teaching Those Humans to Think." (Order from EPA Pollution Prevention Division, 401 M Street SW, Washington, DC 20460.)

17. Baker, N. C. "E-trainers mix carrots and sticks." May 1993. Environment Today 4(5), pp. 1-10.

18. U.S. Department of Energy (DOE). "Pollution Prevention Is Everyone's Job." (Videotape dated September 25, 1993.)

19. Saunders, T., and L. McGovern. 1992. The Bottom Line of Green Is Black. Harper Collins.

20. U.S. Environmental Protection Agency (EPA). Spring 1994. Pollution Prevention Incentives for States. EPA 742-K-93-001. 
21. U.S. Environmental Protection Agency (EPA). October 1993. Pollution Prevention and Right-toKnow in the Government: Executive Order 12856. EPA 100-K-93-001.

22. National Center for Manufacturing Sciences. July 1993. Focus.

23. Thornburg, L. October 1993. "Companies benefit from emphasis on superior customer service." HRMagazine, pp. 46-49.

24. Office of Technology Assessment (OTA), U.S. Congress. February 1990. Making Things Better: Competing in Manufacturing. OTA-ITE-443, U.S. Government Printing Office, Washington, D.C.

25. Flanagan, P. September 1993. “Here come the 'road warriors'." Management Review, pp. $36-40$.

26. "Investing in Community-Based Development." Fall 1993. The Enterprise Foundation, Columbia, Maryland. 
Attachment - Sources for Training Tools 


\section{Attachment - Sources for Training Tools}

\section{Research Institutes/Consulting Groups}

Research institutes provide information and research; sometimes to their paid clientele only, sometimes to the public at large. Consulting groups generally sell services and training workshops. Some also sell hardware/software products.

- An extensive list of consulting, training, and environmental services groups can be found in the regional editions of The Environmental Directory (Ref. 9). Under the category for training companies alone, the directories lists 169 entries. Some examples are:

Waste Reduction Institute for Training and Applications Research, Inc. which publishes the results of its survey, "State Legislation Relating to Pollution Prevention."

Eco-Logical Solutions, a pollution prevention consulting firm founded by Tedd Saunders, co-author of The Bottom Line of Green Is Black.

- Other organizations are:

American Institute for Pollution Prevention

University of Cincinnati

Cincinnati, OH 45221

"founded in June, 1989 under a cooperative Agreement between the EPA and the University of Cincinnati." The mission is to serve as a communication forum among government, industry, academic, and public stakeholders; promote the pollution prevention ethic and work to eliminate disincentives; and identify the trends and issues that define the pollution prevention field.

Northeast-Midwest Institute

218 D Street, S.E.

Washington, DC 20003

(202) 544-5200

publishes studies pertinent to the Northeast and Midwest regions of the country. Prime clients are the relevant members of U.S. Congress and state and city governments.

The Upjohn Institute

$300 \mathrm{~S}$. Westnedge Avenue

Kalamazoo, MI 49007-4686 
"a non-profit research organization devoted to finding and promoting solutions to employment-related problems at the national, state, and local level."

American Petroleum Institute

1220 L Street, NW

Washington, DC 20005

The American Petroleum Institute has established the Pollution Prevention Task Force to "tell the story of pollution prevention from an advocacy and educational standpoint." It facilitates discussion among industry, government, and environmental group representatives. Information can be obtained from:

Finally, a discussion of pollution-prevention education and training needs and opportunities is published in: Freeman, H., T. Harten, J. Springer, P. Randall, M. A. Curran, and K. Stone. "Industrial Pollution Prevention: A Critical Review," 85th Annual Meeting of the Air and Waste Management Association, June 1992.

\section{Department of Energy}

DOE has offices charged with handling environmental restoration and waste management, energy efficiency and renewable energy, and defense programs, among others. Information can be obtained from:

Office of Scientific and Technical Information

P.O. Box 62

Oak Ridge TN 37831

(615) 576-8401

a publishing clearinghouse for DOE reports.

Office of Energy Efficiency and Renewable Energy

1000 Independence Ave., SW

Washington, DC 20585

manages efficiency programs in such areas as industrial technology and building technology.

Office of Defense Programs (DP)

1000 Independence Ave., S.W.

Washington, DC 20585 
publishes a series of pollution prevention guidelines, including:

"Prioritization of Pollution Prevention Options Using a Value Engineering Approach," December 1993

“Model Pollution Prevention Opportunity Assessment Guidance," December 1993.

“Benchmarking the Private Sector, Rev.1," March 1993.

DP has also sponsored conferences and workshops and has published proceedings including:

"U.S. Department of Energy Defense Programs Pollution Prevention Workshop," DOE/DP/00249-H2.

Finally, researchers at Pacific Northwest Laboratory, Westinghouse Hanford Company, Argonne National Laboratory, and Idaho National Engineering Laboratory are developing tools and policies that will facilitate incorporation of pollution prevention opportunities into the design or modification of facilities in the DOE complex. This work promises to yield approaches, tools, and methodologies that can be incorporated into architecture, engineering, and facilities design and refit classes.

\section{Department of the Interior}

The Department of the Interior publishes:

"Department of the Interior, Office of Environmental Affairs Pollution Prevention Handbook: Composting" (No. 8 in a Series of Fact Sheets).

\section{Department of Labor}

The DOL sponsors several efforts regarding workforce training and the improvement of the workplace, including Learning Consortia, a collaboration of the Employment and Training Administration and the Office of the American Workplace and partnerships with community colleges and the National Center for the Workplace.

\section{Environmental Protection Agency}

EPA technical, research and informational documents may be obtained from the:

Center for Environmental Research Information

26 West Martin Luther King Drive

Cincinnati, $\mathrm{OH} 45268$ 
as well as the Risk Reduction Engineering Laboratory at the same address. These include:

EPA Office of Solid Waste and Emergency Response Environmental Fact Sheet: The facts on recycling plastics

Environmental Fact Sheet: Recycling grass clippings

Environmental Fact Sheet: Recycling municipal solid waste: facts and figures

Environmental Fact Sheet: Yard waste composting

List of North American Waste Exchanges

- Ongoing Efforts by State Regulatory Agencies to Integrate Pollution Prevention into Their Activities, EPA/742/B-93/002, 1993.

- State Pollution Prevention Initiatives Utilizing Media-Program Grant Flexibility, EPA 100-R-94-001, March 1994.

- 1993 Reference Guide to Pollution Prevention Resources. EPA 742-B-93/001, 1993.

- Abstracts of Pollution Prevention Case Study Sources. EPA 742-B-94-001, January 1994.

- Summary of Pollution Prevention Case Studies with Economic Data (By SIC Codes). EPA 742-S-94-001, January 1994.

The EPA also maintains a database of professionals to promote networking on various topics related to pollution prevention. Interested parties may join or obtain information by contacting:

Pollution Prevention Information Clearinghouse

Environmental Protection Agency

401 M Street, SW \#3404

Washington, DC 20460

(202) 260-1023, (fax -0178)

EPA documents specifically related to financial tools/analysis are:

- Design for the Environment: Directory of EPA's Environmental Network for Managerial Accounting and Capital Budgeting, EPA 742-B-94-004, May 1994.

- Total Cost Assessment: Accelerating Industrial Pollution Prevention through Innovative Project Financial Analysis, EPA/741/R-92-002, May 1992.

- A Primer for Financial Analysis of Pollution Prevention Projects, EPA/600/R-93/059, April 1993. 
EPA's Office of Pollution Prevention and Toxics publishes a quarterly newsletter of advances and topics in pollution prevention as well as a calendar of relevant workshops, symposia, and expos. Contact:

\section{Pollution Prevention News}

U.S. EPA

401 M Street SW (MC 7409)

Washington, DC 20460

\section{Industry Associations}

National Center for Manufacturing Sciences

3025 Boardwalk

Ann Arbor, MI 48108

(313) $995-0300$

publishes the newsletter, Focus, and develops initiatives for the manufacturing industry. The MCMS has recently launched the Manufacturing Technologies Laboratories program to help students and teachers master the skills needed to be a lifetime learner in the workplace ("School-to-work efforts get a boost with MTL program", Focus, June 1994, p. 4.).

\section{State Agencies}

Fact sheets, information guides, and checklists are available from state waste management agencies. Currently, 45 states and the District of Columbia offer waste management/technology utilization assistance through one or more agencies. These, as well as other resources, are listed in the EPA's 1993 Reference Guide to Pollution Prevention Resources (EPA 742-B-93-001).

Examples of the variety of materials available from state agencies, include:

The Minnesota Office of Waste Management

Fact Sheet: Recycling market development program

Fact Sheet: Waste source reduction checklist

Minnesota Technical Assistance Program

Considerations in Metals Recycling

Fact Sheet: Selecting a still for on-site recycling

Minnesota Pollution Control Agency

Waste Exchange Services: a waste reduction fact sheet 
State of Michigan, Departments of Commerce and Natural Resources, Office of Waste Reduction Services

Fact Sheet: Producing recycled products

Case Study: Recycling pays at Rochester

Fact Sheet: Selecting a supplier, hauler, and materials broker

Fact Sheet: Waste exchange: Everybody wins!

Fact Sheet: Waste reduction checklist

Virginia Department of Waste Management, Virginia Waste Minimization Program

Waste reduction fact sheet

North Carolina Agricultural Extension Service

North Carolina State University

Raleigh, NC 27695-7624

An association of state, county, and local government pollution prevention administrators, as well as interested stakeholders from the federal government and private sector is:

National Roundtable of State Pollution Prevention Programs

P.O. Box 7219

Silver Spring, MD 20910

(301) $495-9278$

which provides lobbying efforts, technical assistance, information, and workshops on training/ education and university-based programs, as well as other topics.

\section{State Extension Services}

Some states have created industrial extension services that provide information and facilitative help to businesses within the state. Help includes leading businesses to state agencies, banks and credit pools, certified consultants, and in-house technical experts. Some services, such as the Michigan Modernization Service, have obtained excellent press for their innovative and eclectic approaches to serving their industrial customers.

\section{Manufacturing Technology Centers}

Manufacturing Technology Centers, established by The Omnibus Trade and Competitiveness Act, provide technological assistance to small- and medium-sized businesses in their region. "The Centers provide a wide range of services including individual project engineering, training courses, TQM 
courses, demonstrations, and assistance in selecting and using software and equipment" (See Ref. 24; p. 108). Centers are located in California, Ohio, Kansas, Michigan, New York, South Carolina, and Minnesota.

Many states sponsor agencies that complement the work of the MTCs for the specific needs of industries within that state. These industrial extension services provide a variety of direct services and will also match businesses with appropriate state agencies and/or consultants (see state agencies above).

\section{Universities}

Freeman et al., in Industrial Pollution Prevention: A Critical Review, note that pollution prevention education is occurring in a variety of academic disciplines, but is concentrated mainly in chemical and environmental engineering departments. Furthermore, the course work available is generally limited to senior-level electives or graduate courses. Pollution prevention concepts are not taught in entry-level courses and are rarely addressed in the social sciences or liberal arts.

This problem is being addressed by the EPA's National Pollution Prevention Center for Higher Education. The Center produces and distributes pollution prevention educational materials in the form of modules that can be incorporated into course work in accounting, architecture, business law, chemical engineering, chemistry, environmental engineering, industrial engineering/operations research, industrial design, marketing, material science, and operations management. The Center also publishes a directory of faculty members who incorporate pollution prevention concepts in their curricula.

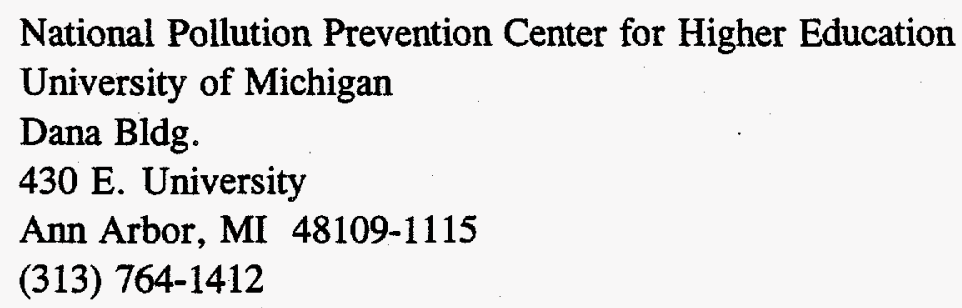

- EADCs/LACs. Small- and medium-sized manufacturing businesses can obtain energyefficiency audits from Energy Analysis and Diagnostic Centers, DOE-sponsored centers housed at 22 universities throughout the country. Senior and graduate-level engineering students perform the audits under the guidance of tenured engineering faculty and provide confidential written reports to the client business. These programs combine the practical experience engineering students need as part of their curriculum with the business needs of industry. The EADC program is currently being expanded to include energy, waste, and productivity assessments in addition to energy audits. These expanded facilities, now in the pilot phase, are called Industrial Assessment Centers (IACs). 
Energy Analysis and Diagnostic Centers (EADCs)

Universities with EADC/IAC** programs are:

Arizona State University

Bradley University

Colorado State University*

Georgia Institute of Technology

Hofstra University

Iowa State University

Mississippi State University

North Carolina State University

Oklahoma State University

Old Dominion University

Oregon State University*

San Diego State University

San Francisco State University

South Dakota State University

Texas A\&M University
Texas A\&M University-Kingsville

University of Arkansas

University of Dayton

University of Florida

University of Kansas

University of Louisville

University of Maine*

University of Massachusetts (Amherst)

University of Michigan

University of Missouri (Rolla)

University of Nevada (Reno)

University of Notre Dame

University of Tennessee*

University of West Virginia

University of Wisconsin (Milwaukee)*

\section{Utilities}

Nearly all utilities provide employee and student awareness aids, demand-side management programs, and information that can be used to train and educate on ee/wr principles.

In addition to information from local utilities, information on innovative programs in utility-based community development can be obtained from:

The Enterprise Foundation

10227 Wincopin Circle

Columbia, MD 21044-9998

(410) 964-1230 


\section{Distribution}

No. of

Copies

\section{OFFSITE}

12 DOE/Office of Scientific and Technical Information

J. Atcheson

U.S. Department of Energy DOE Headquarters

1000 Independence Avenue, SW

Washington, DC 20585

J. Bryson

U.S. Department of Energy

DOE Headquarters

1000 Independence Avenue, SW

Washington, DC 20585

L. German

U.S. Department of Energy

DOE Headquarters

1000 Independence Avenue, SW

Washington, DC 20585

J. Quinn

U.S. Department of Energy DOE Headquarters

1000 Independence Avenue, SW

Washington, DC 20585

M. Quinn

U.S. Department of Energy

DOE Headquarters

1000 Independence Avenue, SW

Washington, DC 20585
No. of

Copies

J. Romm

U.S. Department of Energy

DOE Headquarters

1000 Independence Avenue, SW

Washington, DC 20585

L. Sousa

U.S. Department of Energy

DOE Headquarters

1000 Independence Avenue, SW

Washington, DC 20585

R. Vallario

U.S. Department of Energy

DOE Headquarters

1000 Independence Avenue, SW

Washington, DC 20585

\section{ONSITE}

DOE Richland Operations Office

D. D. Green (K8-50)

57 Pacific Northwest Laboratory

R. E. Lewis (K8-23)

N. L. Moore (50) (K8-04)

Publishing Coordination

Technical Report Files (5) 